\title{
OS TRADUTORES DA CASA DO ARCO DO CEGO E A CIÊNCIA ILUMINISTA: A CONCILIAÇÃO PELAS PALAVRAS 1
}

\section{THE TRANSLATORS WORKING AT CASA DO ARCO DO CEGOAND THE ENLIGHTENED SCIENCE: CONCILIATION THROUGH WORDS}

\section{Alessandra Ramos de Oliveira Harden*}

\section{RESUMO}

Entre 1799 e 1801, funcionou em Lisboa a Casa Literária do Arco do Cego. Voltada para a publicação de obras científicas e didáticas ligadas à aplicação das ciências naturais, a Arco do Cego foi dirigida pelo frei José Mariano da Conceição Veloso, naturalista brasileiro e tradutor incansável. Para realizar o objetivo de trazer o progresso para o reino português por meio da instrução, as atividades da Arco do Cego ocorreram dentro de um sistema de mecenato em que a coroa portuguesa arcava com as despesas dos projetos. Essas despesas incluíam aquelas referentes ao pagamento dos tradutores recrutados por Frei Veloso, como Manoel Jacinto Nogueira da Gama, matemático, filósofo naturalista e professor que traduziu obras nas áreas de matemática e engenharia. As traduções publicadas sob a supervisão de Veloso eram introduzidas por dedicatórias e prefácios de tom laudatório escritos pelos tradutores, que assim reconheciam seu débito com a monarquia e declaravam sua fidelidade à Coroa e às tradições portuguesas. O objetivo deste trabalho é mostrar que esses paratextos funcionaram como instrumentos para a aceitação dos princípios científicos iluministas, pois as ideias progressistas eram apresentadas aos leitores portugueses por discursos comprometidos com as tradições do antigo regime português e com a retórica escolástica.

Palavras-chave: tradução; ciência iluminista; retórica

\section{ABSTRACT}

Between 1799 e 1801, the publishing house Casa Literaria do Arco do Cego was fully active in Lisbon and dedicated to publishing scientific and didactic works regarding the application

*. UNB, Brasília (DF), Brasil. oliveira.ales@gmail.com

1. Algumas considerações preliminares acerca do tema deste artigo foram apresentadas no V CIATI - Congresso Ibero-Americano de Tradução e Interpretação em 2010, durante comunicação intitulada Tradutores brasileiros e iluminismo português: retórica de conciliação. 
of natural scientific knowledge. It was run by Friar José Mariano da Conceição Veloso, a Brazilian naturalist and tireless translator. To accomplish its aim of bringing progress to the Portuguese kingdom through instruction, Arco do Cego held its activities within a system of patronage in which the Portuguese crown would pay for all of its expenses, including the payment of the translators working for Veloso. One of these translators was Manoel Jacinto Nogueira da Gama, a mathematician, naturalist and lecturer who translated works in the areas of mathematics and engineering. The translations published under Veloso's supervision were introduced by dedicatories and prefaces written in a laudatory tone by the translators, who through such paratexts acknowledged their debt to the Crown and declared their loyalty to the monarchical regime and traditions of the Portuguese society. In this paper, the aim is to show that the translators' paratexts worked as tools for the acceptance of the enlightened scientific principles, because the progressive ideas were presented to the Portuguese readers by discourses written in accordance with the scholastic tradition.

Keywords: translation; enlightened science; rhetorics

\section{INTRODUÇÃO}

Uma das consequências do desenvolvimento dos Estudos da Tradução nos últimos anos foi o crescente interesse na história e historiografia da tradução. Cada vez mais, os pesquisadores da tradução sentem a necessidade de olhar para o passado e tentar explicar como a tradução, os tradutores e as obras traduzidas estão ligados aos acontecimentos que moldaram diferentes culturas (DELISLE; WOODSWORTH, 1995; CRONIN, 1996; PYM, 1998; MILTON, 2002; MONTGOMERY, 2002; WYLER, 2003; RODRIGUES, 2010).

É dentro desse contexto de pesquisa historiográfica que se insere este trabalho, em que se examinam aspectos específicos da atuação de tradutores durante um episódio muito especial da trajetória luso-brasileira: a tradução de obras técnico-científicas na Casa Literária do Arco do Cego na virada do século XVIII para o XIX.

O enfoque da discussão feita neste artigo recai não nas traduções em si, mas nos paratextos redigidos pelos tradutores ${ }^{2}$ (dedicatórias e prefácios) para acompanhar muitas das obras vertidas para o português. Este estudo filia-se, assim, a uma linha de investigação dos estudos de tradução voltada à análise dos para textos tradutórios, cujo interesse é motivado pela oportunidade única, aberta por esses

2. Neste artigo, foi mantida a grafia empregada pelos autores dos textos escritos em português dos séculos XVIII e XIX. 
escritos, de se ter acesso à voz do tradutor, que se revela em primeira pessoa ao apresentar o texto traduzido. São tentativas de trazer à luz relações entre o tradutor e outros agentes textuais, contextos de produção do original e da tradução e outros aspectos relevantes. Além disso, por impedirem o apagamento da experiência tradutória, os paratextos do tradutor podem ser considerados como uma forma de proteger a própria história do texto e de sua tradução. São muitos os estudiosos que têm se dedicado a esse tipo de investigação no âmbito da pesquisa em tradução, entre os quais podem ser mencionados Hermans (1996), Tahir-Gürçağlar (2002), Pym (2004), Frank (2007) e Rodrigues (2009).

O objetivo é mostrar que os paratextos dos tradutores foram essenciais para a introdução da ciência iluminista no reino de Portugal, pois foi por meio deles que os tradutores da Arco do Cego conseguiram cumprir sua tarefa de tornar o conhecimento alcançado por nações como França e Inglaterra aceitável na sociedade lusitana. Ou seja, seu sucesso foi devido não só à atividade tradutória propriamente dita, mas à retórica utilizada nos paratextos.

Para tanto, fez-se a análise de prefácios e dedicatórias de autoria de José Mariano da Conceição Veloso e de Manoel Jacinto Nogueira da Gama, dois dos tradutores da Arco do Cego. O primeiro foi o mais prolífero tradutor da casa, com pelo menos 44 obras traduzidas; o segundo, foi legítimo representante dos filhos do Brasil enviados à Universidade de Coimbra, para quem a passagem pela Arco do Cego foi apenas um dos serviços prestados à Coroa (OLIVEIRA HARDEN, 2010). O pressuposto aqui é que esses dois homens representam o espírito dos tradutores da Casa no que diz respeito ao papel da tradução no contexto social e cultural da Lisboa do final do século XVIII.

$\mathrm{O}$ artigo foi organizado da seguinte maneira: primeiramente, apresentam-se brevemente a Casa do Arco do Cego e os tradutores que redigiram os paratextos analisados; em seguida, faz-se a discussão com a ajuda de trechos retirados de alguns prefácios e dedicatórias dos tradutores.

\section{A CASA DO ARCO DO CEGO: A FUNÇÃO DA TRADUÇÃO E A TAREFA DOS TRADUTORES}

A Casa Literária do Arco do $\mathrm{Cego}^{3}$ foi fundada em 1799 e manteve suas atividades até 1801, quando foi incorporada "com todas as suas Officinas, e

3. O nome da tipografia foi frequentemente alterado para incorporar mudanças nas suas instalações: de Oficina da Casa Litterária do Arco do Cego passou, em fases diferentes, a Typographia (Chalcográphica) (Typoplástica) (e Litterária) da Casa (Litterária) do Arco do Cego. 
pertences" à Impressão Régia (PORTUGAL, 1801, s.p.). Sabe-se que, nesse curtíssimo espaço de tempo, a Arco do Cego esteve envolvida na publicação de pelo menos 83 títulos, das quais 45 no mínimo foram traduções para o português de obras em francês, inglês, alemão, italiano, espanhol e latim, que apresentassem conhecimentos úteis ao reino nas áreas de ciências naturais aplicadas (FARIA, 1999, p. 116-7).

As atividades da Arco do Cego inseriram-se em um projeto político maior do governo português, de cunho progressista, idealizado pelo ministro da Marinha e Domínios Ultramarinhos Dom Rodrigo de Sousa Coutinho. Nesse contexto, a Arco do Cego pode ser vista como um "empreendimento de regime" (DOMINGOS, 1999, p. 92) ou como a "tradução" (CURTO, 1999, p. 49) do projeto de Coutinho, cujo objetivo era colocar Portugal no nível de desenvolvimento científico exibido por nações como França e Inglaterra (WEGNER, 2004).

Para a história da tradução, o estabelecimento da Arco do Cego é de especial relevância, pois foi a primeira agência de tradução financiada pelo Estado na história de Portugal (WYLER, 2003, p. 76). Os registros contábeis das despesas da tipografia revelam que, em geral, os tradutores e autores recebiam o mesmo pagamento: "200 exemplares da respectiva obra, ou o seu valor em dinheiro, se revendessem à Casa a 'mercadoria' recebida" (LEME, 1999, p. 82). Além disso, os tradutores podiam contar com "aposentamento no edifício, compreendendo as despesas de mesa" (FERNANDES PINHEIRO, 1874 citado por LEME, 1991, p. 81-2).

O encarregado pela administração da Casa era o Frei José Mariano da Conceição Veloso, naturalista autodidata brasileiro nascido em Minas Gerais e amante dos livros e do conhecimento. Sob sua tutela, a Arco do Cego "transformouse no principal estabelecimento de publicação de livros científicos e didáticos na época, apesar da vida curtíssima que teve" (OLIVEIRA HARDEN, 2009, p. 134). A atuação de Veloso na Arco do Cego se deu em várias frentes: além de administrador, ele foi tradutor, editor, revisor e coordenador de traduções. Foram muitas as suas traduções, sempre ligadas à sua preocupação com a ciência e suas aplicações. Seu maior feito no que diz respeito ao seu ofício de tradutor foi a série O Fazendeiro do Brazil - o cultivador, publicada em partes entre 1798 e 1806. São 10 volumes de textos nas áreas de interesse econômico para Portugal (cana de açúcar, café, cacau, especiarias, tinturaria e cordoaria), escritos por diversos autores, em línguas diversas, traduzidos por Veloso e dirigidos ao Brasil, como indica o título da série (OLIVEIRA HARDEN, 2009; FARIA, 1999).

$\mathrm{Na}$ sua dedicatória-prefácio do primeiro tomo de O Fazendeiro do Brasil - o Cultivador, em que o tópico é a cana-de-açúcar, Veloso esclarece ao seu leitor qual é o seu objetivo com a tradução que apresenta. De fato, a passagem do prefácio tem 
o efeito de justificar todo o projeto subjacente à criação da Tipografia e, em última instância, revelar ao leitor o que se esperava das traduções. Veloso declara ter sido

\begin{abstract}
incumbido, a saber: de ajuntar e trasladar em português todas as memórias estrangeiras que fossem convenientes aos Estabelecimentos do Brasil, para melhoramento da sua economia rural e das fábricas que dela dependem, pelas quais ajudadas houvessem de sair do atraso e atonia em que atualmente estão e se pusessem ao nível com os das nações nossas vizinhas e rivais no mesmo continente, assim na quantidade como na qualidade dos seus generos e produções. (VELOSO, 1798, p. i)
\end{abstract}

A tradução é vista, então, como parte do esforço progressista que tomava conta do governo e da elite intelectual lusitana. A crença iluminista no poder dos livros e da instrução é a base para o moto que guiou a vida de Veloso e as atividades da Arco do Cego e pode ser encontrado na dedicatória-prefácio para outra de suas traduções: "Sem livros não há instrução" (VELOSO, 1800, p. iv).

A função social da tradução de possibilitar o acesso ao conhecimento que parecia distante dos súditos do reino português e escondido nos mistérios das línguas estrangeiras foi também objeto de prefácios escritos por outro tradutor da Arco do Cego, Manoel Jacinto Nogueira da Gama. Naturalista e matemático formado pela Universidade de Coimbra, Nogueira da Gama traduziu apenas três obras, nas áreas de matemática e engenharia (OLIVEIRA HARDEN, 2010). Apesar de sua pequena produção tradutória, aparentemente foi o único dos tradutores ligados a Veloso e à Arco do Cego que se preocupou em fazer da tradução o tópico de um de seus prefácios, um 'Discurso do Traductor' que acompanhava a obra Reflexões sobre a metapbysica do calculo infinitesimal (1798), uma tradução do texto do francês Lazare Carnot que havia sido publicado em Paris em 1797.

Em seu Discurso ${ }^{4}$, Nogueira da Gama defende o uso da tradução como a única forma de fazer conhecidos os avanços da ciência, já que estes ocorriam em múltiplas línguas e a grande velocidade. A tradução, embora lenta, era o único caminho:

E acaso saõ as Traducções hum recurso proporcionado ao inconveniente, e embaraço, que resultaõ da diversidade das línguas? De nenbum modo os saõ [...] estaõ as Traducções bem longe de poderem com os seus passos sempre vagarosos, e tardios acompanhar a marcha veloz dos conhecimentos humanos [...]. Mas sem dúvida saõ o unico [...]. (1798, p. ix-x) (grifos meus)

4. No texto de Nogueira da Gama, há ecos frequentes das palavras do iluminista Jean Rondo d'Alembert acerca do papel da tradução e das línguas no desenvolvimento da ciência (OLIVEIRA HARDEN, 2010). 
Nogueira da Gama lembra ao leitor desse seu prefácio, de 16 páginas e longos períodos, as vantagens trazidas pela tradução, que podem ser resumidas na passagem abaixo:

As Traducções naõ só nos abrem os thesouros, e franqueaõ as preciosidades, que possuem as linguas antigas, e modernas, mas facilitando a aquisiçaõ dos conhecimentos, e descobertas dos Estrangeiros, nos poem, e nos conservaõ ao nivel de todas as Nações cultas, e sabias: espalhaõ o gosto das Sciencias: fazem conhecer as suas applicações, e vantagens: mostraõ os interesses, que dellas pódem tirar no moral, e no physico o homem em particular, e a Sociedade em geral: enriquecem as linguas com bum grande numero de termos technicos, e expressões adoptadas pelos Sabios: e finalmente fazem ás mesmas Sciencias o grande serviço de darem occasiaõ a desenvolverem-se genios, que aliás ficariaõ perdidos com hum dano irreparável. (1798, p. xi-xii) (grifos meus)

Se facilitar a aquisição dos conhecimentos dos estrangeiros era o papel da tradução, a tarefa do tradutor que trabalhava no âmbito do projeto capitaneado por Veloso era fazer com que o texto traduzido fosse aceito pela comunidade de leitores portugueses. O problema é que isso não dependia só da habilidade linguística e do conhecimento técnico que os tradutores supostamente possuíam. A inserção de textos da ciência iluminista em uma sociedade tradicionalista, em que muitos dos princípios do Iluminismo não podiam ser discutidos e os censores estavam sempre atentos a qualquer publicação que trouxesse vestígios dos pensamentos dos "perigosos filósofos franceses" (MARTINO; SAPATERRA, 2006; ABREU, 2003, p. 21-87), exigiu cuidados a mais dos tradutores e de Frei Veloso, responsável pelas publicações.

A tarefa de apresentar o ideário iluminista de forma aceitável aos portugueses e, claro, às autoridades portuguesas foi cumprida pelos tradutores por meio dos paratextos anexados às traduções. Mais que meramente apresentar o texto traduzido, o paratexto do tradutor

constitui entre o texto e o entretexto uma zona não apenas de transição, mas também de transação: lugar privilegiado de uma pragmática e de uma estratégia, de uma ação sobre o público, a serviço, bem ou mal compreendido e acabado, de uma melhor acolhida do texto e de uma leitura mais pertinente [...]. (GENETTE, 2009, p. 10) (grifo no original).

Os paratextos tradutórios se colocam, assim, como as ferramentas ao dispor dos tradutores para convencer os leitores e as autoridades do reino da utilidade das obras traduzidas. Mais importante e em uma instância mais sutil, são o momento em que o tradutor pode dar garantias de que a ciência importada não oferecia ameaça ou risco às tradições e costumes portugueses. Para tanto, o uso da retórica foi decisivo, como será demonstrado com a discussão de características específicas 
dos paratextos escritos por Veloso e Nogueira da Gama, os dois tradutores que são considerados representativos da equipe de tradutores da Arco do Cego para os fins da argumentação feita neste artigo.

\section{PREFÁCIOS E DEDICATÓRIAS: CIÊNCIA E RETÓRICA}

Nos prefácios e dedicatórias produzidos por Veloso e por Nogueira da Gama, a voz do tradutor é expressa por meio de recursos retóricos poderosos que não deixam dúvidas quanto ao comprometimento de seus autores com o projeto editorial financiado pelo governo português. São textos com alto grau de subjetividade nos quais os tradutores continuamente recorrem a figuras de linguagem para enfatizar as questões que abordam, convencer os leitores da relevância da obra traduzida que introduzem e, acima de tudo, persuadir tais leitores da magnanimidade do príncipe português, Dom João VI.

Há uma aparente contradição discursiva na relação entre paratexto e texto principal, já que textos prefaciais com alto grau de subjetividade são empregados para apresentar traduções de obras científicas fundamentadas nos princípios do Iluminismo. Os dois conjuntos de textos envolvidos nesse jogo, os paratextos dos tradutores, de um lado, e as obras traduzidas, de outro, foram redigidos de acordo com tradições textuais que se opõem. Enquanto os cientistas (ou filósofos naturalistas), autores dos textos originais, usavam a língua em conformidade com um paradigma de experimentalismo, racionalidade e objetividade característico do Iluminismo, os tradutores brasileiros escreviam seus textos seguindo um modelo de eloquência derivado da retórica escolástica, criticada pelos iluministas por sua dependência da chamada auctoritas e pelo uso de linguagem pomposa e ornamentada supostamente em detrimento da argumentação racional.

As traduções publicadas sob a égide da Arco do $\mathrm{Cego}^{5}$ são marcadas por essa curiosa combinação. Trata-se de uma situação em que a relação entre paratexto e texto principal é também uma relação entre o tradicionalismo da retórica escolástica e o reformismo das novidades iluministas. O efeito desse jogo é relevante em dois níveis.

Em primeiro lugar, ele subverte a ideia do Iluminismo como uma ruptura com a tradição, já que revela, em termos discursivos e editoriais, como o ideário iluminado era manipulado de forma a se enquadrar em estruturas de poder e práticas

5. Veloso criou uma rede de tipografias para dar conta das publicações das obras traduzidas por ele e pelos outros tradutores da Arco do Cego. A informação bibliográfica das obras mostra o 
textuais convencionais. Nesse sentido, as conexões feitas pelos prefácios expõem, sem sombra de dúvida, o débito que os cientistas e letrados luso-brasileiros têm com o antigo regime português. Dessa perspectiva, a experiência portuguesa com o Iluminismo é mais de continuidade que de ruptura, de negociação entre o antigo e o novo, entre o universo das palavras caras usadas em grandiloqüentes deferências e o mundo da linguagem descritiva dos experimentos científicos.

Em um nível complementar, os paratextos dos tradutores funcionam como os mecanismos que possibilitam essa negociação. Caracterizados pelo uso da oratória epidítica para demonstrar a gratidão pelo apoio e pelas benesses distribuídos pelo patrono, os prefácios e dedicatórias escritos pelos tradutores tiveram o efeito de apresentar as novas ideias e técnicas iluminadas em um tipo de discurso aceitável pela cultura de chegada. De fato, embora inseridos em um contexto de censura política e religiosa, Veloso e os tradutores em sua equipe conseguiram publicar obras fundamentadas em bases epistemológicas e metodológicas que ainda não eram vistas com bons olhos em Portugal por sua ênfase no empirismo, uso da razão e pensamento autônomo.

Por se manterem obedientes às regras que regiam a sociedade lusitana da época, os tradutores responsáveis por verter os paradigmas científicos iluminados para a língua portuguesa foram capazes de conectar discursivamente o tradicional e o novo. Estabeleceram um espaço texto entre o antigo regime português e os princípios do Iluminismo, transportando para o papel o poder que, no 'mundo real', pertencia a agentes sociais como censores e representantes do governo, ou seja, o poder de determinar o que as pessoas deveriam e/ou poderiam ler e/ou traduzir, e o que deveria ser proibido ou evitado.

A análise dos paratextos dos tradutores mostra que o continuísmo e a obediência à tradição resultaram do fato de os tradutores terem adotado um estilo construído dentro da tradição escolástica do sistema educacional lusitano: a retórica escolástica era ensinada na Universidade de Coimbra e, no Brasil, nas escolas jesuítas e demais instituições de formação católicas. Moldados por anos de treinamento na retórica escolástica, Veloso e Nogueira da Gama redigiram textos prefacionais que, embora pareçam exagerados ao leitor de hoje, provavelmente não causavam surpresa aos leitores de então.

envolvimento dos seguintes estabelecimentos lisboetas no projeto editorial de Veloso e Coutinho, além da Arco do Cego: Officina Simão Thaddeo Ferreira, Officina (Patriarcal) João Procópio Correa da Silva, Officina Antonio Rodrigues Galhardo, Régia Officina Typographica, (Impressão Régia). Essas 'Officinas' eram usadas para a impressão das páginas já preparadas por Veloso (ver DOMINGOS, 1999, p. 96-97). 
Veloso era um religioso e já havia ensinado retórica, e esse seu treinamento explica muitas das características de seus textos. Não era, porém, o único a ter familiaridade com a retórica, já que a educação recebida por Nogueira da Gama (e pelos demais tradutores da Arco do Cego), antes e durante sua passagem pela Universidade de Coimbra, foi marcada pela escolástica e pelas práticas retóricas.

O emprego da linguagem para convencer a audiência é a principal característica do método de ensino escolástico, que predominou no Colégio das Artes e na Universidade de Coimbra. Como as aulas do Colégio eram requisitos para a entrada nessa Universidade, é válido afirmar que o pensamento escolástico influenciou o ensino universitário português mesmo após a reforma curricular de 1772. É possível que a influência dessas duas instituições - Colégio das Artes e Universidade de Coimbra - tenha mantido Portugal isolado do progresso científico alcançado em outras partes da Europa, pois nelas os estudiosos "ocupavam-se em disputationes escolásticas, citando como autoridades últimas, além da Bíblia, Aristóteles e Santo Tomás" (CARVALHO, 2000, p. 131).

Mesmo a reforma dos currículos da Universidade de Coimbra, ocorrida em 1772 por ordem do Marquês de Pombal, não foi forte o bastante para diminuir a força da retórica no universo cultural e intelectual lusitano. É certo que um novo currículo foi adotado, o qual incluía as ciências naturais e a filosofia natural, em um esforço de aproximar aquela que era a única universidade do império português aos avanços metodológicos e epistemológicos alcançados no restante da Europa.

O novo estatuto da Universidade proibia expressamente a retórica escolástica, que foi banida da universidade e de todas as instituições de ensino do reino português por "se compozer de quastões quodlibeticas, metafysicas, abstractas, e inuteis, que com sofismas interminaveis se disputam pela affirmativa, e pela negativa" (UNIVERSIDADE DE COIMBRA, 1772, vol. 3, p. 2, § 4). Não se condenou a retórica per se, somente aquelas práticas retóricas da escolástica jesuítica consideradas vazias. A retórica 'útil', ao contrário, foi defendida por Luis Antonio Verney, frei oratoriano que forneceu as bases para a reforma educacional portuguesa com sua obra Verdadeiro método de estudar, publicada originalmente em Nápoles em 1746 (MAXWELL, 1995, p. 12). Verney era um partidário do método experimental e abominava a argumentação baseada na auctoritas. Para ele, a retórica era um instrumento poderoso para apresentar os resultados obtidos pela experimentação; não deveria, portanto, ser reduzida ao uso de figuras de linguagem, mas empregada como os alicerces nos quais as ideias eram construídas. Nesse sentido, é válido afirmar que a reforma da universidade, inspirada pela obra de Verney, teve o efeito de reforçar a relevância da retórica, vista agora como necessária em todas as esferas da vida e em todas as áreas de estudo. 
Mesmo assim, a retórica escolástica, baseada nas lições de Aristóteles, continuou muito influente. Aparentemente manteve o seu status como a arte da comunicação e persuasão, ou como "o poder, diante de quase qualquer questão que nos é apresentada, de observar e descobrir o que é adequado para persuadir" (ARISTÓTELES, 2011, p. 44-5).

Persuadir e envolver o leitor são os principais objetivos dos paratextos elaborados por Veloso e Nogueira da Gama. A linguagem é usada como estratégia para convencer o leitor da habilidade intelectual do autor do paratexto, a qual, em última instância, funciona como garantidora do valor da argumentação apresentada, já que a persuasão resulta do "caráter pessoal do orador, quando o discurso é proferido de tal maneira que nos faz pensar que o orador é digno de crédito", pois é maior a confiança do leitor em "pessoas de bem" (ARÍSTOTELES, 2011, p. 45). O convencimento do leitor de que o autor é uma pessoa "de bem" depende, em parte, do uso que esse autor faz da linguagem: escrevendo de forma a demonstrar erudição e conhecimento.

Assim fizeram Veloso e Nogueira da Gama, que exibiram suas habilidades retóricas e produziram prosa de tessitura complexa, com períodos longos repletos de orações intercaladas e inversões. São textos abundantes em figuras de linguagem, especialmente hipérboles, metáforas, comparações, contrastes e repetições de períodos em construções paralelas, como comprovam os trechos citados adiante. Além disso, há o recurso a outras obras e autores ('autoridades') na tentativa de corroborar os argumentos construídos nos paratextos, com citações da Bíblia, de Virgílio e de outras fontes praticamente inquestionáveis naquela época, feitas de acordo com a prática da disputatio típica da escolástica.

O prefácio-dedicatória de Veloso para o seu O Fazendeiro do Brazil tomo I, parte I (1798) é um bom exemplo no que se refere aos mecanismos retóricos frequentemente utilizados. O entusiasmo de Veloso com o projeto de tradução e publicação de obras sobre agronomia (na época conhecida como economia rural) fica evidente, e ele compõe um texto de 35 parágrafos e longos períodos, alguns dos quais se arrastam por 15 linhas. Com citações e referências a Milton, Horácio e Virgílio, o texto toca repetidamente em temas ligados à agricultura, à generosidade do príncipe e à fidelidade dos vassalos (particularmente dos nascidos no Brasil), como no seguinte trecho:

\footnotetext{
Abençôe, e prospere o Ceo as sabias, e luminosas determinações de V. ALTEZA, espalhando, e derramando a mãos cheias milhares de felicidades, e bens sobre os póvos, que tem a dicta, e honra de mandarem a confissão da sua vassallagem ao Supedaneo do Throno de V. ALTEZA [...] e permitta me V. ALTEZA que eu dos pés de V. ALTEZA possa bradar aos meus
} 
conterraneos.

O fortunatos nimium, si sua bona norint, Agricolas!

Virgil.

Para apoiar seus argumentos com relação à cultura da cana-de-açúcar e à produção do açúcar, Veloso menciona diferentes autores, entre os quais estão aqueles que escreveram textos que foram traduzidos e incluídos nas duas partes deste tomo de O Fazendeiro do Brazil: Brian (Bryan) Edwards, Philip Miller, E. A. Wilhelm von Zimmermann e Jeronymo Vieira de Abreu (cujos trabalhos estão incluídos na Parte I, tomo I), e Jacques-François Dutrône, Henri Louis Duhamel du Monceau (com textos incluídos na Parte II, tomo I). A seguir, tem-se a reprodução de um dos longos parágrafos do prefácio de Veloso.

Neste [volume], que pertence à cultura das Canas do Assucar, e ao seu fabrico, apresento a VOSSA ALTEZA os Extractos do Livro V, de Brian Edward, sobre a Jamaica; 'do Cap. XXIX e XXX, do American Husbrandy [sic]; dos Artigos das Canas de Miler, e de varias outras Rapsodias, concernentes ao mesmo objecto, [...] a final da noticia da arvore Assucareira, tirada de Zimmerman, e de huma Folha Ingleza, supprindo, o que naõ traziaõ estes papeis, a respeito da sua terebração, ou sangria, com o que copiei do Abbade Valemont na sua Obra Curiosites sur la vegetation. Conclui tudo com o plano da Reforma das moendas, picadeiros, e fornalhas, proposta no Rio de janeiro por Jeronymo Vieira de Abreu. (VELOSO, 1798, p. ii-iii)

A palavra de Deus é citada, por exemplo, na publicação sobre tinturaria e a cultura da indigoeira (Indigofera tinctoria, também conhecida como anileira), O Fazendeiro do Brazil, tomo II, parte II, publicado em 1800. Na página de rosto, Veloso faz uma citação do Livro do Êxodo: "Hyacinthum, Purpura, Coccigera. Ex. Cap. xxv. V. 17". Trata-se de uma passagem da Vulgata, sobre as instruções referentes às oferendas que deveriam ser feitas a Deus, e o objetivo de Veloso parece ser ressaltar a preciosidade dos corantes: o texto em latim faz a relação entre a palabra byacintho e a cor azul (ou um azul com traços de púrpura) e entre a coccigera (cochonilha) e a cor carmim. $\mathrm{O}$ frei tradutor retorna ao tema da epígrafe em sua dedicatória-prefácio:

O fabrico do azul, o da purpura, o da cochonilha, são tão dignos da alta contemplação de $\mathrm{V}$. A. R., e da sua immediata protecção, como podem, e devem ser o ouro, a prata \&C., pois huns e outros são igualmente pertences da Soberania, que o Todo-Poderoso conferio na Pessoa de V. A. R. (VELOSO, 1800, p. vi)

Ele acrescenta ao seu argumento a relação entre a cor azul e o texto bíblico: 
A côr azul he de tanta estimação nas Divinas Letras, que só no Exodo se acha repetida trinta vezes, debaixo da palavra Thecheleth que a vulgata verte byacinthinum, pela côr azul do Jacintho. (VELOSO, 1800, p. vii)

Da mesma forma, os paratextos de Nogueira da Gama são um testemunho de sua maestria retórica. O texto abaixo é a sua dedicatória para o Príncipe Dom João VI, anexada a sua tradução Ensaio sobre a theoria das torrentes e rios, uma obra voltada para a engenharia hídrica. $\mathrm{O}$ texto todo consiste de apenas um parágrafo, com dois longos períodos, o primeiro dos quais chega a 36 linhas.

Senhor

Se a verdadeira Gloria dos Soberanos consiste na felicidade, que procuraõ à seus Vassalos: Se Luís XIV firmou o seus gloriosoThrono no coraçaõ dos Póvos, que governou, e fez immortal o seu nome pelas vantagens, que lhes grangeou: Se Pedro I, seguindo diversa vereda, da que trilharão seus Predecessores, mereceo o titulo de Grande mais que tudo pela regeneração, que fez de huma Naçaõ barbara e inculta, passando-a do nada a hum estado luminoso, infundindo-lhe o gosto das Sciencias, da Insustria e do Commercio, e procurando-lhe todas as commodidades, de que gozaõ as Nações civilizadas: Se Frederico II, nos últimos annos da sua gloriosa carreira promovendo o Commercio, as Artes, e as Sciencias, administrando prompta e imparcial Justiça, socorrendo dos desgraçados, e consumindo parte de suas rendas em úteis Estabelecimentos, merceceo a admiriaçaõ do Universo, a adoraçaõ de seus Vassallos, e o respeito de seus poderosos Inimigos, mais do que pelos prodigios da Arte, e do Valor, com que à testa de suas regeneradas Tropas havia triunfado em Friedberg, Rosbac, e Bressau: VOSSA ALTEZA REAL, desde o feliz momento, em que principiou a Reger seus Vassallos, unicamente occupado em mantellos em huma perfeita tranquilidade, a pezar da triste perturbaçaõ do Universo, promovendo a Industria, animando o Commercio, patrocinando a Agricultura, protegendo as Artes, honrando as Sciencias, amando os Sabios, espalhando com maõ larga conhecimentos e luzes de todas as classes, e conduzindo os ao estado de esplendor e riqueza, em que se achaõ, com muita razão merece o titulo de Grande. Conheça o assim o Mundo, que assim o attesta o amor, o respeito, e a lealdade de todos os seus venturosos Vassallos, entre os quaes humildemente prostrado beija as Regias Mãos

De VOSSA ALTEZA REAL

O mais reconhecido e fiel Vassallo

Manoel Jacinto Nogueira da Gama (NOGUEIRA DA GAMA, 1800a, s.p.)

Nogueira da Gama recorre a mecanismos retóricos específicos para seduzir seu leitor. O longo período do texto é basicamente formado por orações condicionais iniciadas por "Se" e que só têm seu sentido complementado no final; é aí que o leitor descobre que o Príncipe Dom João VI está sendo comparado com outros monarcas e que é merecedor do título de "Grande". Com exceção da primeira oração, em que a condicional é construída em volta de uma ideia mais geral 
— a glória dos monarcas —, a estrutura do período é 'Se A é considerado/realizou B, então $C$ pode ser considerado D'. 'A' é sempre um monarca esclarecido (Luís XIV, Pedro I, Frederico II,), 'B' refere-se às qualidades ou aos feitos atribuídos a tal monarca, 'C' é o Príncipe Dom João é 'D' é o direito de ser chamado 'Grande'. $\mathrm{O}$ resultado do paralelismo (repetição da estrutura) é uma tensão que permanece suspensa e prende a atenção do leitor até ser finalmente resolvida com a oração principal, em que o tradutor declara que o Príncipe português merece ser chamado de "Grande", com mais justificativa ainda que os 'grandes' monarcas citados no texto. Nogueira da Gama monta sua argumentação com base em fatos conhecidos e tomados como reais, já que os monarcas que menciona eram já famosos por suas ideias progressistas e por seus papeis ativos como patronos das artes e das ciências. Assim, como o pressuposto é, em princípio, aceitável e correto, a conclusão também parece correta e lógica, pelo menos em nível textual: o Príncipe Dom João VI só pode ser ainda maior que Luis XIV, Pedro I e Frederico II.

Estratégias para envolver o leitor em um diálogo com o autor também são usadas por Nogueira da Gama em sua "Prefacçaõ do Traductor", mais um texto elaborado para acompanhar a tradução Ensaio sobre a theoria das torrentes e rios. Há agora passagens com interrogações dirigidas aos leitores e referências a situações problemáticas com que esses leitores podem se identificar, como nos trechos a seguir, em que árvores, águas e pedras ganham traços humanos (catacrese):

[...] he tambem necessario saber obstar aos estragos, que as aguas dos rios, das torrentes, e das torrentes-rios causaõ, principalmente no tempo das suas grandes cheias. Quando terrenos da mais singular fertilidade passaõ à servir de leitor aos rios, ou saõ reduzidos à estereis e aridas dunas? Quantas lavouras, unica esperança do cançado lavrador, desapparecem para sempre cobertas por duros calhaus, e ingrato saibro? Quanta arvores preciosas, já pelo seu fructo, já pela natureza do seu lenho, saõ desarreigadas e facilmente acarretadas pela violencia das aguas, que zombaõ da sua corpulencia e vigor? Quantos edificios de grande valor e prestimo saõ derrubados? (NOGUEIRA DA GAMA, 1800b, s.p.)

A filiação de Veloso e Nogueira da Gama à tradição portuguesa ligada ao humanismo e à retórica significa que esses dois cientistas e tradutores estavam muito cientes do poder da linguagem como instrumento de persuasão. Nesse sentido, é interessante observar como sempre incluíam em seus prefácios sinais dos novos tempos, leves pinceladas linguísticas da ideologia iluminista. São numerosas as ocorrências de imagens e expressões associadas à dicotomia luz/sombra, e à relação entre nação e felicidade (especialmente à noção de felicidade do povo) quando o trecho em questão faz referência à monarquia e ao império português. De um lado, palavras como 'luzes', 'illuminados', 'luminosas luzes' etc. são empregadas para 
enfatizar as habilidades intelectuais e administrativas do Príncipe Dom João IV. De outro, vocábulos relacionados a felicidade são usados para descrever o estado do reino português durante o governo do Príncipe. A tradução também aparece ligada à felicidade dos portugueses, já que os tradutores a colocam como a condição futura daqueles afetados pelas traduções e, portanto, também pelas ordens do Príncipe, sob auspícios de quem as traduções eram, afinal, feitas e publicadas. Novamente, Veloso oferece bons exemplos:

VOSSA ALTEZA, pelo contrario, abre a luminosa carreira do seu illuminado governo, procurando estabelecer o bem real de todos os seus vassallos, sobre as solidissimoas bases da bem entendida Agricultura. (VELOSO, 1798, p. xii)

$[\ldots]$

Abençõe, e prospere o Ceo as sabias, e luminosas determinações de V. ALTEZA, espalhando, e derramando a mãos cheias milhares de felicidades, e bens sobre o póvos, que tem a dicta, e honra de mandarem a confissaõ da sua vassallagem ao supedaneo do throno de V. ALTEZA, de qualquer ponto do Globo, em que vivem, por mais distante que este seja [...]. (VELOSO, 1798, p. xxxii)

Em um contexto de censura e desconfiança acerca das ideias iluministas, Veloso e Nogueira da Gama adotaram, em sua retórica quase barroca, elementos do vocabulário da iluminada república das letras. A intenção óbvia era mostrar sua filiação ao lado prático do Iluminismo (utilitarismo) e, por consequência, a adesão do Príncipe às ideias iluministas úteis. Ao acomodar elementos lexicais associados às luzes em seus discursos, os tradutores produziram textos híbridos, que tematizam o progresso e a ciência mas também falam de vassalos e de intervenção divina, que desejam a felicidade de todos os povos do reino português mas pressupõem o trabalho escravo de indígenas e africanos no Brasil para que essa felicidade seja alcançada, como mostra um passagem de outro dos prefácios de Veloso, dessa vez sobre a cultura do algodão:

Augmentar esta cultura [do algodão], SENHOR, he beneficiar o genereo humano; porque tende a cobrillo de sua desnudez [...] passa imediatamente a cobrir na mesma America a tantos centos de milhares de individuos Aborigenes, e Africanos, que chamão a V.A.R. Seu REI, Seu SENHOR, que, sem liberdade, sic vos non vobis, são os braços dos Europeos, quer para catear Minas, quer para a mesma Lavoura. Elles são o todo, e o tudo destes trabalhos. Sem elles nada he positivo. Outro vestido não os cobre. Prouvesse a Deos que ainda este mesmo se lhe não distribuisse com huma mão tão escassa! (VELOSO, 1806, s.p.) ${ }^{6}$

6. A expressão 'sic vos non vobis' refere-se àqueles que trabalham mas não se beneficiam dos frutos de seu trabalho. Acredita-se ser parte de poema de Virgílio: Hos ego versiculos feci, tulit alter honores/ Sic vos non vobis fertis aratra boves; / Sic vos non vobis mellificatis apes; / Sic vos non vobis vellera 
Essa contradição parece ter sido uma característica geral do Iluminismo em Portugal, e pode ser mais bem entendida se for abandonado o conceito tradicional de Iluminismo como um movimento filosófico fundamentado somente em princípios racionalistas compartilhados por uma elite europeia.

O Iluminismo esteve longe de ser unitário e unicamente racionalista, pois muitos de seus representantes acreditavam que a chave para o conhecimento repousava mais no experimentalismo que na própria razão. Além disso, não se limitou à Europa ou aos escritos de uma elite. Tratou-se de fenômeno mais rico e complexo, que afetou diferentes nações - tanto na Europa quanto em outros continentes em graus e maneiras diversas, atingiu grupos sociais e profissionais distintos e influenciou diferentes aspectos da vida social (PORTER, 2001; OUTRAM, 1995).

No que diz respeito ao caso lusitano, o poder da igreja católica, a religiosidade e o misticismo da população, além, é claro, do forte sistema monárquico e absolutista, motivaram alegações de que o Iluminismo em Portugal teria sido menor ou por demais comprometido com o poder. Os termos comumente utilizados com referência à experiência iluminista lusitana já indicam o viés: Iluminismo Católico, Ilustração de Compromisso e Ecletismo.

No entanto, as novas interpretações do que foi o Iluminismo levaram a um questionamento do uso desses termos e das pressuposições que a eles estão subjacentes. Se o impacto do ideário iluminista variou em função da cultura da nação ou comunidade que o adotava, não há motivo para pensar a experiência lusitana como destoante ou menos significativa que aquela de qualquer outra nação. Estudos mostram, por exemplo, que os iluminados do império português seguiram os mesmos princípios científicos que seus colegas franceses em termos de métodos e experimentos (CARVALHO, 2008) e que a nova forma de pensar em Portugal foi estimulada pelos feitos intelectuais de Descartes, Newton e Locke, autores geralmente vinculados ao Iluminismo como um todo (MAXWELL, 1995, p. 10). Assim, a expressão Iluminismo Português passa a ganhar força como denominação da "conciliação entre o ideário filosófico-cientista moderno e os dogmas da tradição católica" (CARVALHO, 2008, p.126), que incluíam a filosofia e a retórica escolástica.

fertis oves $/$ / Sic vos non vobis nidificatis aves. Em português: "Eu fiz estes pequenos versos, outrem levou deles as honras, e louvores/ Assim como não para vós, ò aves, os ninhos fabricais probre, mas gratos/ Assim como não para vós, overlhas, trazeis da fina lã os brancos vélos; / Assim como não para vós, abelhas, fazeis o doce mel nos doces favos;/Assim como não para vós, novilhos, os arados trazeis ao jugo humildes" (Tradução de Leonel da Costa, publicada em 1761). 
Por conseguinte, o que se quer propor aqui é que o movimento de tradução de textos científicos e técnicos coordenado por Veloso seja entendido como um dos fatores que contribuíram para moldar o Iluminismo português, dentro desse processo de conciliação mencionado por Carvalho. Os tradutores envolvidos, atuando como agentes do antigo regime português e dentro de seus dogmas culturais - e textuais -, apresentaram ao mundo lusitano a ciência dos iluminados sem criar conflitos com esse regime, o que facilitou a aceitação dos novos princípios científicos.

Dessa perspectiva, a relevância das traduções técnico-científicas elaboradas com a benção do Príncipe Dom João VI vai além da utilidade e importância dos textos traduzidos. Do ponto de vista histórico (inclusive, claro, no que concerne à história e à historiografia da tradução), essas traduções confirmam a grande proximidade entre o antigo regime português (colonial, monárquico, escravocrata) e o Iluminismo. Nesse sentido, é significativa a inexistência, em Portugal e em suas colônias, de traduções (publicadas) de textos iluministas de conteúdo político revolutionário: foi por meio dos textos científicos que o Iluminismo chegou a Portugal, e isso se deu também por meio do trabalho e da astúcia dos tradutores de textos 'úteis' voltados à ciência aplicada.

As dedicatórias e prefácios escritos pelos tradutores da Arco do Cego são exemplos da arena simbólica em que o moderno e o tradicional se encontram. Esses paratextos mostram como os intelectuais luso-brasileiros conseguiram introduzir o Iluminismo de forma razoavelmente tranquila e segura em uma sociedade que talvez não estivesse tão receptiva às luzes estrangeiras. $\mathrm{O}$ recurso à retórica tradicional certamente desempenhou papel essencial no estabelecimento de um ambiente textual favorável, que, sem questionar os papéis sociais tipicos da sociedade portuguesa, deixava claro que o conhecimento vindo das nações mais civilizadas chegava aos portugueses por meio de ações da Coroa. Um trecho de texto de Nogueira da Gama mostra aos seus leitores a relação entre o monarca e a divulgação desse conhecimento ao descrever Dom João VI como

[h] um Principe pelos Ceos destinado á Naçaõ Portugueza para conduzilla a passos rapidos állem do esplendor das mais civilisadas e poderosas de todo o Universo: Hum Principe unicamente occupado deste grande objecto, no curto tempo decorrido, desde o feliz começo da sua Illuminada Regencia, tendo prodigiosamente derramado por todas as classes dos seus venturosos Vassallos os conhecimentos e luzes, de que necessitavaõ, naõ podia deixar de sentir as grandes vantagens, que resultariaõ de hum judicioso emprego das Aguas. (1800b, s.p.) 


\section{CONCLUSÃO}

Ao longo da história, o conhecimento, a ciência e o progresso (científico, politico etc.) chegaram às sociedades da forma e no ritmo que essas sociedades permitiam ou tinham a capacidade de absorver, de acordo com suas tradições culturais, sociais e políticas. Para o reino português, o caminho possível foi a apresentação do progresso cientifico em embalagens aceitáveis (paratextos), em que se inscreviam todas as demonstrações formais de sujeição e filiação à Coroa Portuguesa e, portanto, ao pacto colonial. A retórica dos paratextos garantiu a circulação e recepção das novidades do Iluminismo ao estabelecer um canal de negociação entre o familiar e o novo. Essa foi a principal tarefa dos tradutores da Casa Literária do Arco do Cego durante o período de pouco mais de dois anos em que a Casa funcionou. Assim, esses homens abriram à língua portuguesa a riqueza contida nas línguas estrangeiras, como descreveu Nogueira da Gama:

\footnotetext{
As Traducções naõ só nos abrem os thesouros, e franqueaõ as preciosidades, que possuem as linguas antigas, e modernas, mas facilitando a aquisiçaõ dos conhecimentos, e descobertas dos Estrangeiros, nos poem, e nos conservaõ ao nivel de todas as Nações cultas, e sabias: espalhaõ o gosto das Sciencias: fazem conhecer as suas applicações, e vantagens: mostraõ os interesses, que dellas pódem tirar no moral, e no physico o homem em particular, e a Sociedade em geral: enriquecem as linguas com hum grande numero de termos technicos, e expressões adoptadas pelos Sabios: e finalmente fazem ás mesmas Sciencias o grande serviço de darem occasiaõ a desenvolverem-se genios, que aliás ficariaõ perdidos com hum dano irreparável. (Nogueira da Gama, 1798c: xi-xii)
}

Assim, os paratextos tradutórios (prefácios e dedicatórias) constituíram estratégia textual conciliatória que permitiu a introdução de certos aspectos do Iluminismo na sociedade portuguesa e, portanto, a consolidação das reformas iniciadas na década de 1750 e que incluíram as mudanças do currículo da Universidade de Coimbra e do papel da retórica escolástica.

\section{BIBLIOGRAFIA}

ABREU, M. (2003). Os Caminhos dos livros. Campinas: Mercado de Letras/Associação de Leitura do Brasil/FAPESP.

ARISTÓTELES (2011). Retórica. Trad. Edson Bini. São Paulo: EDIPRO.

CARVALHO, F. R. (2008). Um Iluminismo Português? A reforma da Universidade de Coimbra (1772). São Paulo: Anablume. 
CARVALHO, J. M. (2000). História intelectual do Brasil: a retórica como chave de leitura. TOPOI - Revista de História, v. 1, pp. 123-152. Disponível em < http://www. revistatopoi.org/numeros_anteriores/topoi01.htm >. Acesso em 15 set. 2011.

CRONIN, M. (1996). Translating Ireland: translation, languages, cultures.Cork: Cork University Press.

CURTO, D. R. (1999). D. Rodrigo de Souza Coutinho e a Casa Literária do Arco do Cego’. In: Campos, M. F. Campos (org.), A Casa Literária do Arco do Cego: Bicentenário. Lisboa: Biblioteca Nacional e Imprensa Nacional, Casa da Moeda, pp. 15-49.

DELISLE, J.; WOODSWORTH, J. (orgs.) (1995) Translators through bistory. Philadelphia: Jonh Benjamins/UNESCO.

DOMINGOS, M. D. (1999). Mecenato político e economia da edição nas oficinas do Arco do Cego'. In: Campos, F. M. G. (org.), A Casa Literária do Arco do Cego: Bicentenário. Lisboa: Biblioteca Nacional e Imprensa Nacional, Casa da Moeda, pp. 91-106.

FARIA, M. F. (1999). Da facilidade e da ornamentação: a imagem nas edições do Arco do Cego. In: Campos, F. M. G. (org.), A Casa Literária do Arco do Cego: Bicentenário. Lisboa: Biblioteca Nacional e Imprensa Nacional, Casa da Moeda, pp. 107-137.

FERNANDES PINHEIRO, J. F. (1874). Memórias do Visconde de São Leopoldo: José Feliciano Pinheiro'. Revista do Instituto Histórico e Geográfico Brasileiro. v 37, nº 49 (Parte $\left.2^{a}\right)$, pp. 5-69.

FRANK, H. T. (2007). Cultural encounters in translated children's literature: images of Australia in French translation. Manchester: St. Jerome.

GENETTE, G. (1987). Paratextos editoriais. Trad. Álvaro Faleiros. Cotia (SP): Ateliê Editorial, 2009.

HERMANS, T. (1996). The Translator's Voice in Translated Narratives. Target. v. 8, nº.1, pp. $23-48$.

LEME, M. O. R. P. (1999). Um breve itinerário editorial: do Arco do Cego à Impressão Régia’. In: Campos, M. F. (org.), A Casa Literária do Arco do Cego: Bicentenário. Lisboa: Biblioteca Nacional e Imprensa Nacional, Casa da Moeda, pp. 77-90.

MARTINO, A.; SAPATERRA, A. P. (2006). A censura no Brasil do século XVI ao século XIX. Estudos Lingüísticos, v. 15, pp. 234-243. Disponível em <http://www.usp.br/ proin/download/artigo/artigos_censura_brasil.pdf>. Acesso em: 20 set. 2011.

MAXWELL, K. (1995). Pombal, paradox of the Enlightenment. Cambridge: Cambridge University Press.

MILTON, J. (2002). O Clube do Livro e a tradução. Bauru: Editora da Universidade do Sagrado Coração.

MONTGOMERY, S. L. (2002). Science in translation: movements of knowledge through cultures and time. Chicago - London: University of Chicago Press.

NOGUEIRA DA GAMA, M. J. (1798). Discurso do Tradutor. In: Carnot, L., Reflexões sobre a metaphysica do calculo infinitesimal. Trad. Manoel Jacinto Nogueira da Gama. Lisboa: Off. João Procopio Correia da Silva, pp. iii-xvi. 
NOGUEIRA DA GAMA, M. J. (1800a). Dedicatória. In: Fabre, M. et al., Ensaio sobre a theoria das torrentes e rios. Trad. Manoel Jacinto Nogueira da Gama. Lisboa: Off. Patriarcal João Procopio Correia da Silva, s.p.

NOGUEIRA DA GAMA, M. J. (1800b). Prefação do Traductor. In: Fabre, M. et al., Ensaio sobre a theoria das torrentes e rios. Trad. Manoel Jaciento Nogueira da Gama. Lisboa: Off. Patriarcal João Procopio Correia da Silva, s.p.

OLIVEIRA HARDEN, A. R. (2009). Brasileiro tradutor e/ou traidor: Frei José Mariano da Conceição Veloso. Cadernos de Tradução. v. 1, n. 23, pp.131-148. Disponível em: $<$ http://www.periocos.ufsc.br/index.php/traducao/article/view/12203>. Acesso em: 19 set. 2011.

OLIVEIRA HARDEN, A. R. (2010). Manoel Jacinto Nogueira da Gama: ciência e tradução no final do século XVIII. Tradução em Revista. v. 1, pp. 1-19. Disponível em: < http:// www.maxwell.lambda.ele.puc-rio.br/trad_em_revista.php? strSecao $=$ input0 $>$. Acesso em: 20 set. 2011.

OUTRAM, D. (1995). The Enligbtenment. Cambridge: Cambridge University Press.

PORTER, R. (2001). The Enlightenment. $2^{\text {nd }}$ ed. Basingstoke: Palgrave.

PORTUGAL (1801). Decreto de 7 de dezembro de 1801. In: Silva, A. D. (org.), Collecção da legislação portugueza desde a última compilação das ordenações. Lisboa: Typografia Maigrense, 1828. Disponível em <http://www.iuslusitaniae.fcsh.unl.pt>. Acesso em: 19 set. 2011.

PYM, A. (1998). Method in translation bistory.Manchester: St. Jerome.

PYM, A. (2004). The moving text: localization, translation, and distribution. Amsterdam: Benjamin

RODRIGUES, C. C. (2009). Prefácios e notas de tradutores brasileiros dos anos 1930 a 1950. Tradução em Revista. v. 7, pp. 01-13. Disponível em: http://www.maxwell.lambda. ele.puc-rio.br/trad_em_revista.php?strSecao =input0. Acesso em: 02 Nov 2011.

RODRIGUES, C. C. (2010). Ō papel da tradução na pesquisa científica brasileira: primeiros movimentos. Tradução em revista. v. 8, pp. 1-13. Disponível em: http://www.maxwell. lambda.ele.puc-rio.br/trad_em_revista.php?strSecao=input0. Acesso em: 02 Nov 2011.

TAHIR-GÜRÇAĞLAR, Ş. (2002). What texts don't tell: the uses of paratexts in translation research'. In: Hermans, T. (ed.), Crosscultural transgressions: research models in translation studies II: bistorical and ideological issues. Manchester: St. Jerome, pp. 44-60.

UNIVERSIDADE DE COIMBRA (1772). Estatutos, Livro III - Dos cursos das sciencias naturaes, e filosoficas'. In: Universidade de Coimbra (1972), II Centenário da Reforma Pombalina-Estatutos da Universidade de Coimbra (1772). Coimbra: Imprensa da Universidade.

VELOSO, J. M. C. (1798). Dedicatória-Prefácio. In: Veloso, J. M.C. (ed.), O fazendeiro do Brazil: cultivador (etc.). Tomo I, Parte I (Da Cultura das Canas e da Factura do Assucar). Trad. José Mariano da Conceição Veloso. Lisboa: Régia Officina Typographica., pp. 1-32. VELOSO, José M. da C. (1800). Dedicatória-prefácio. In: Raieau, B., O fazendeiro do Brazil: cultivador (etc.). Tomo II. Tinturaria. Parte II. Cultura da indigoeira, e extracção da sua fecula. Trad. José Mariano da Conceição Veloso. Lisboa: Off. Simão Thaddeo Ferreira, s.p. 
VELOSO, J. M. C. (1806). Dedicatória-prefácio. In: Veloso, J. M. C. (ed. e trad.), O Fazendeiro do Brazil: cultivador (etc.). Tomo V. Filatura. Parte I. Trad. José Mariano da Conceição Veloso. Lisboa: Impressam Regia, s. p.

WEGNER, R. (2004). Livros do Arco do Cego no Brasil Colonial. História, Ciências, SaúdeManguinhos. v. 11, sup. 1, pp. 131-40. Disponível em <http://www.scielo.br/pdf/ hcsm/v11s1/06.pdf>. Acesso em: 19 set. 2011.

WYLER, L. (2003). Linguas, poetas e bacharéis: uma crônica da tradução no Brasil. Rio de Janeiro: Ed. Rocco.

Recebido: 21/09/2011

Aceito: 02/11/2011 